SINET: Ethiop. J. Sci., 23(1):103-113, 2000

(c) Faculty of Science, Addis Ababa University, 2000

ISSN: 0379-2897

Short communication

\title{
TENSIONAL FISSURES IN SEDIMENTS AS SIGNATURE OF RIFT TECTONICS IN THE MAIN ETHIOPIAN RIFT
}

\author{
Laike Mariam Asfaw \\ Geophysical Observatory, Faculty of Science, Addis Ababa University \\ PO Box 1176, Addis Ababa, Ethiopia
}

\begin{abstract}
The Main Ethiopian Rift, which forms the northern part of the East African Rift, is a regime of extensional tectonics with geodetically measured mean spreading rate of $3.6 \mathrm{~mm}(\mathrm{yr})^{-1}$. Earlier studies have shown that the effects of this extension are manifested mainly through earthquakes, faults and volcanism. Recently, with the observations of the occurrence of fissures of tectonic origin on the sediment cover of the rift floor, an additional effect of the extensional process has been identified. The importance of this effect in characterizing rift tectonics could be commensurate with the areal size of the sedimentary cover of the rift floor which is substantial. The object of this study is to assess the significance of these tectonic-induced fissures as signature of the rifting process by comparing them to earthquake and volcanic activities. It is shown that fissures on sediments are significant indicators of rift tectonics with a corresponding role as agents of strain release.
\end{abstract}

Key words/phrases: Earthquakes, fissures, sediments, signature, strain release, tectonics

\section{INTRODUCTION}

The Main Ethiopian Rift (MER) is characterized by Mohr (1967) as a volcanotectonic lineament extending from $4^{\circ}$ north to $9^{\circ}$ north. Mohr has shown that this rift has a rift-in-rift structure which he called the Wonji Fault Belt (WFB). Faults in the WFB have orientations ranging between $\mathrm{N}-\mathrm{S}$ and $\mathrm{N} 20^{\circ} \mathrm{E}$ and occur within border faults forming the rift margins and having orientations ranging from $\mathrm{N}^{\circ} 5^{\circ} \mathrm{E}$ to $\mathrm{N} 40^{\circ} \mathrm{E}$ (Bonini et al., 1997; Boccalettti et al., 1998). Since the work of Mohr several investigators have studied the rift from different 
perspectives (Searle and Gouin, 1972; Di Paola, 1970, 1972; Mohr et al., 1981; Gidey Woldegebriel et al., 1990; Abera Alemu, 1992; Ebinger et al., 1993; Fekadu Kebede and Kulhanek, 1994; Bekele Abebe et al., 1997; Atalay Ayele, 1998; Bilham et al., 1999) characterizing the extension with respect to seismicity, gravity anomaly, geodesy, volcanology and structural geology.

From gravity study Searle and Gouin (1972) showed that the central part of the MER is characterized by gravity high. Later, more detailed work in the region showed that there is a relative positive anomaly superposed on the Bouguer anomaly following the WFB. This corresponds to anomalous mantle intrusion into the lower crust generating the younger volcano-tectonic lineaments (Abera Alemu, 1992) which are the most recent signatures of the extensional tectonics.

Geodetic measurements over the last thirty years (Mohr, 1981; Bilham et al., 1999) have shown that the MER has a mean extension rate of $3.6 \mathrm{~mm}(\mathrm{yr})^{-1}$ in agreement with the middle Miocene age and $50 \mathrm{~km}$ mean width of the MER (Di Paola, 1970; Lloyds, 1977).

A study of the distribution and age of volcanism (Morton et al., 1979) in the region has shown riftward younging of volcanic activity with the youngest volcanoes in the MER being active recently. This decrease in age has been attributed by these authors to crustal necking which is induced by extension.

Structural geological investigation (Bekele Abebe et al., 1997; Bonini et al., 1997; Boccaletti et al., 1998) in the MER showed that EW extension of the rift induces sinistral motion on rift floor faults generating pull-apart features at several locations. The results of these authors agree with focal mechanism study of earthquakes in the region which are of strike-slip (sinistral) and normal faulting varieties (Shudofsky, 1985; Atalay Ayele, 1998).

On the other hand the occurrence of tectonically induced fissures on sediments in the MER has been reported since the 1950s (Gouin and Mohr, 1967; Gouin, 1971; Laike M. Asfaw, 1982; 1998). These fissures have morphologies of either linear zone of subsidence or pits connected by cracks (Fig. 1) and in both cases have lengths up to a few kilometres, depths of several tens of meters and widths of up to few meters. 

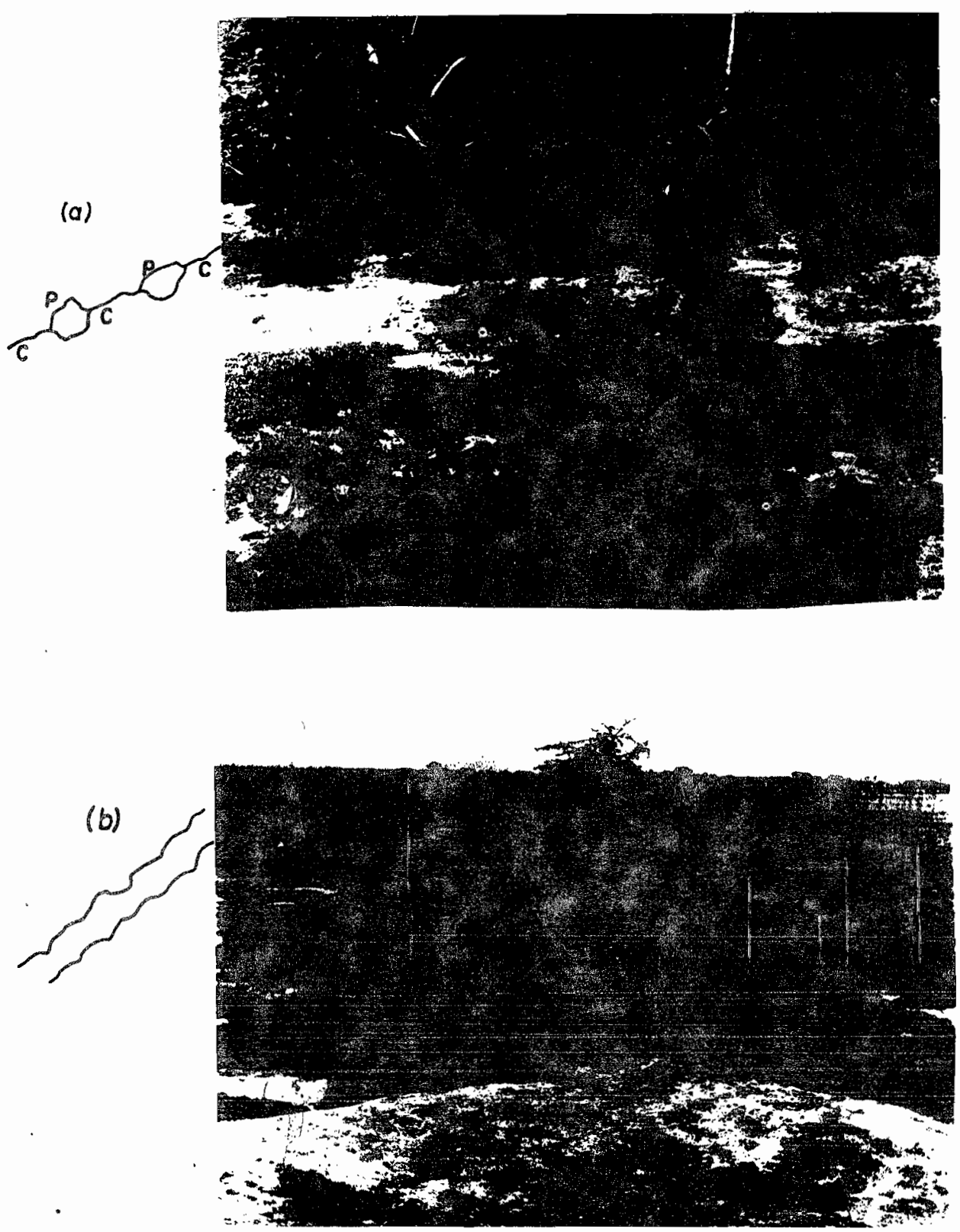

Fig. 1. Morphology of sedimentary fissures: a) Subsidence pits (P) connected by cracks (C) and b) Linear zone of subsidence in the Main Ethiopian Rift near Lake Awasa (MER). 
The development of a fissure starting from the earthquake swarm that induced the initial cracks on sediments to fully developed fissures characterized by pits connected with cracks or linear zone of subsidence under subsurface erosion has been monitored over a period of six months in the northern part of the MER (Laike M. Asfaw, 1982). A similar manifestation of sedimentary fissures in the region, in 1971, has been attributed to swarm of earthquakes that occurred few months earlier (Gouin, 1971). In all cases of observation the orientation of these fissures consistently follows the rift axis indicating their tectonic origin (Williams, 1981).

In general the sudden occurrence of such fissures as a result of subsidence has not been directly related to earthquakes. Where earthquakes could be attributed to the initial cause the manifestation of the fissures is offset in time by several months from the causative earthquakes. As Figure 2 shows earthquake epicentres with $M \geq 5$ in the MER do not correlate with the location of sedimentary fissures in general. No volcanicity has been associated with the occurrence of such sedimentary fissures.

\section{SIGNIFICANCE OF SEDIMENTARY FISSURES AS SIGNATURE OF RIFT TECTONICS COMPARED TO EARTHQUAKES AND VOLCANOES}

The earthquake history of the MER (Gouin, 1979; Laike M. Asfaw, 1986) shows that several large earthquakes have occurred in the region. Earthquake data exist for the MER since 1900 and almost all damaging earthquakes have been reported since then. On the other hand reports of sedimentary fissures have been received since the 1950 s only. Whereas a large earthquake is felt over wide areas away from the epicentre, the occurrence of a large fissure affects the immediate surrounding only. If there are no settlements or construction in the immediate neighbourhood during the occurrence of a large fissure the event could pass unnoticed. In this manner the number of fissures reported since the 1950 s could be far below the total number of actual occurrences.

Quantitative estimate of the relative importance of sedimentary fissure as signature of rift tectonics could be made by utilizing the data of their occurrence starting from the 1950s (Laike M. Asfaw, 1998). 

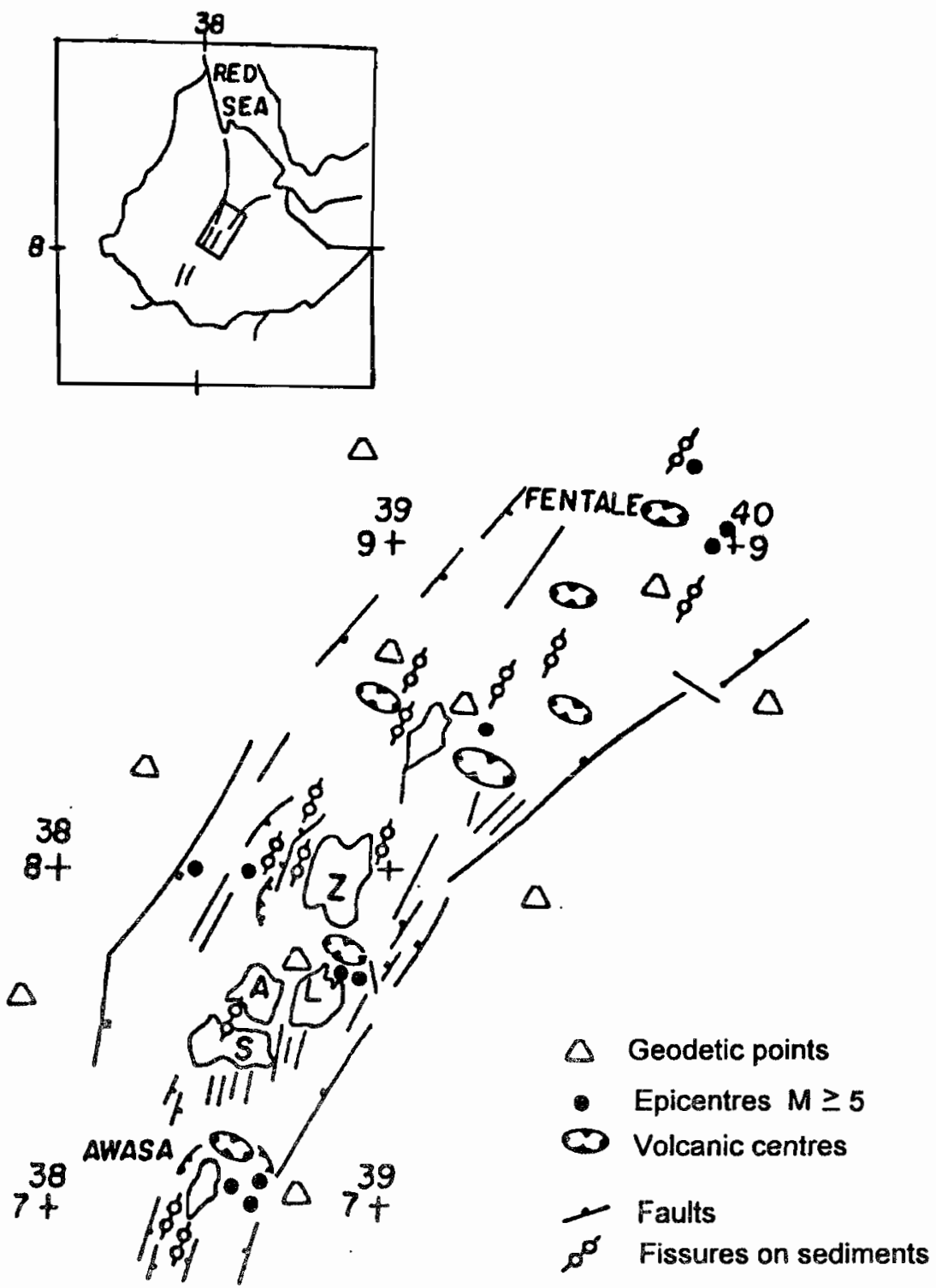

Fig. 2. The Main Ethiopian Rif showing distribution of volcanic centres, earthquake epicentres, sedimentary fissures, major faults and geodetic markers. A, Lake Abiata; $\mathbb{L}$, Lake Langano; S, Lake Shala; $Z$, Lake Ziway. 
From the records of their occurrence sedimentary fissures could be considered as rare events just like earthquakes. For example, in comparing the probability of occurrence of fissures with that of earthquakes space and time windows must be defined in counting fissure events. In this respect fissures that occur en echelon or parallel in a given locality at a given time or in rapid succession of time within a given locality will be considered as one event.

With this observation the occurrence of sedimentary fissures of tectonic origin could be assumed to satisfy the Poisson distribution. This would imply that no two fissures occur in rapid succession of time or too closely together in space. However if this is not obeyed and fissures occur closely in space and time then the manifestation will be assumed to be a single event.

From published data (Laike M. Asfaw, 1998) and one additional occurrence of fissure since then between Lakes Abiata and Shala (Fig. 2) there have been a total of 13 reports of sedimentary fissures in the past 45 years in the MER. This is a rate of about $0.3(\lambda=0.3)$ fissure per year and represents the mean rate of occurrence of fissures in the Poisson process which is assumed to be the governing distribution. This probability distribution is given in the form:

$$
P(n)=\left\{[\operatorname{Exp}(-\lambda x)](\lambda x)^{n}\right\} / n !
$$

where $P(n)$ is the probability of the occurrence of $n$ fissures in $x$ years at a given site prone to the occurrence of sedimentary fissures. For example, the probability of the occurrence of a single fissure at any given site in fissure prone areas in a given year is $P(1)=\{[\operatorname{Exp}(-0.3)](0.3)\}=0.22$. Therefore there is $22 \%$ chance that a fissure will occur at a given site in a fissure prone area.

On the other hand the probability of the occurrence of damaging earthquakes, of say magnitude $M \geq 4$, in any one year in the same region could be found based on the earthquake data of the MER (Gouin, 1979; Laike M. Asfaw, 1986; Atalay Ayele, 1998). Again assuming Poisson distribution which is a valid assumption (Epstein and Lomnitz, 1966) for distribution of earthquakes we obtain $29 \%$ probability. Taking note of the fact that not all fissures have been reported this shows that the probability of occurrence of fissures in areas of sedimentary cover in the MER is significant compared to earthquakes. 
Regarding volcanism though no volcano monitoring exists for the MER the most recent eruption in the region occurred about 150 years ago and involved the area adjacent to the volcanic mountain Fentale (Gibson, 1967). In the southern section of the MER it has been reported by Di Paola (1972) that the activities of two young volcanoes in the Awasa caldera (Fig. 2) namely Chabbi and Urji are in fumarolic stage. The $\mathbf{0 . 2 2}$ probability for the occurrence of fissure implies one event in about 4 to 5 years whereas the last volcanic eruption was over 180 years ago.

Therefore sedimentary fissures occur far more frequently than volcanic activity of any significance and their rate of occurrence compares favourably with those of earthquakes. This makes them an important signature of rift tectonics.

\section{MODE OF STRAIN RELEASE IN THE MER}

Records of earthquakes in the MER since 1900 (Gouin, 1979; Laike M. Asfaw, 1986; Atalay Ayele, 1998) show that strain release through seismicity by earthquakes of magnitude 4 and above falls too short to account for the total strain accumulation inferred from geodetic measurements. This strongly suggests a mode of strain release by earthquakes with magnitude below 4 and also through aseismic movements at pre-existing faults and fissures.

No felt earthquakes $(M>3)$ have been directly associated with the occurrence of sedimentary fissures. On the other hand their manifestation in direct association with microearthquakes $(M<3)$ is not ruled out.

Strain release by earthquakes with magnitude greater than 6.0 accounting for the accumulated strain is unlikely over short span of time. This is because the occurrence of such earthquakes in the region is rare. For example, the last occurrence of such an earthquake $(M=6.8$ ) was in 1906 (Gouin, 1979).

Both micro earthquake survey (Molnar et al., 1970) and geodetic measurements in the MER show the episodicity of strain release (Laike M. Asfaw et al., 1992). This implies different episodes and modes of strain release. 
In this respect strain release must be occurring in the MER significantly through aseismic movements and in relation to micro earthquakes. Strong support for this comes from the occurrence of sedimentary fissures of tectonic origin.

The second mode of strain release is by earthquakes in the magnitude range, 4.0 $\leq M \leq 6.0$. These form all the earthquakes felt in the region. Statistical study of the recurrence of earthquakes in this magnitude range has been made by Fekadu Kebede and Kulhanek (1994) and Atalay Ayele (1998). Low b-value of 0.5 to 0.7 have been obtained by these authors indicating the mode of strain release through preponderance of low magnitude earthquakes compared to large earthquakes. The low b-value also indicates high stress in the crust in the region.

The third possible mode of strain release is by rare large earthquakes with $M$ $>6.0$.

\section{DISCUSSION AND CONCLUSION}

Quaternary volcanism, faulting, tensional fissures on hard rocks, earthquakes and geodetically measured extension rates have been the main indicators of the tectonic activity in the East African Rift in general and in the MER in particular. Now sedimentary fissures which occur relatively more frequently, indicating tensional separation in the rift, must be added to these set of signatures of rift tectonics.

Unlike earthquakes, volcanism and faulting, the occurrence of sedimentary fissures could pass unnoticed unless observed by their effects on existing constructions and settlements. This implies that the role of sedimentary fissures in the overall process of rift tectonics in the MER must have been underestimated. With the recognition of sedimentary fissures as signatures of the tectonics of the MER the picture of the level of tectonic activity in the region must change. In particular, as a substantial surface of the rift floor is under sediments the effect of rift tectonics on the sediment cover could be a significant indicator of the spreading process. Ultimately it is the rift floor that is widening so that other effects of the extensional. process on the sediments must also be sought. 
Almost a continuous chain of sedimentary fissures have appeared in the MER between $7^{\circ} \mathrm{N}$ and $9^{\circ} \mathrm{N}$ in the past 45 years. If the geodetically measured extension rate of $3.6 \mathrm{~mm}(\mathrm{yr})^{-1}$ goes entirely to create cracks then this amounts to creating a void which has to be filled somehow by lowering the overall topographic height of the rift floor. Though erosion and deposition from the adjacent plateaus could compensate this the essence is the overall lowering of elevation.

Though not reported to date the occurrence of tectonic cracks on rift sediments in arid areas developing to fissures is not ruled out by this study. In fact several features which could correspond to sedimentary fissures in arid zones exist to the north of the MER. The exact cause of these features has not been studied yet. If such fissures exist their manifestation and development will not be as spectacular as those discussed here.

\section{ACKNOWLEDGMENTS}

The Author thanks the Swedish Agency for Research Cooperation with Developing Countries (SAREC) and the Ethiopian Science and Technology Commission (ESTC) for making it possible to carry out this work. I thank one anonymous referee for helpful suggestions to improve the manuscript.

\section{REFERENCES}

1. Abera Alemu (1992). The gravity field and crustal structure of the Main Ethiopian - Rift. PhD thesis: Royal Institute of Technology, Sweden, TRTA/GEOD-92/1026. $126 \mathrm{pp}$.

2. Atalay Ayele (1998). Seismicity and earthquake source mechanism study in the East African Rift. PhD thesis, Department of Earth Sciences, Uppsala Univensity.

3. Bekele Abebe, Boccaletti, M., Mazzuoli, R., Bonini, M., Tortorici, L. and Trua,

- T. (1997). Geological Map of the Lake Ziway-Asela Region (Main Ethiopian Rift)., 1:50,000 scale, Consiglio Nazionale delle Ricerche, A.R.C.A., W Kirenze.

4. Bilham, R., Bendick, R., Larson, K., Mohne, P., Braun', J., Samson Tesfiye and Laike M. Asfaw (1999). Secular and tidal atrain across the Main Eethiopian Rift. Geophys. Res. Lett. 26(18):2789-2792. 
5. Boccaletti, M., Bonini, M., Mazzuoli, R., Bekele Abebe, Piccardi, L. and Tortorici, L. (1998). Quaternary oblique extensional tectonics in the Ethiopian Rift. Tectonophysics 287:97-116.

6. Bonini, M., Souriot, T., Boccaletti, M. and Brun, J.P. (1997). Successive orthogonal and oblique extension episodes in a rift zone: Laboratory experiments with application to the Ethiopian rift. Tectonics 16(2):347-362.

7. Di Paola, G.M. (1970). Geological-geothermal report on the central part of the Ethiopian Rift Valley. Report: Ethiopian Geological Survey, Addis Abeba, p. 46.

8. Di Paola, G.M. (1972). Geology of the Corbetti caldera. Bull. Volcanologique 35(2):497-506.

9. Ebinger, C.J., Tesfaye Yemane, Gidey Woldegebriel, Aronson, J.L. and Walter, R.C. (1993). Late Eocene-Recent volcanism and faulting in the southern Main Ethiopian Rift. J. Geol. Soc. London 150:99-108.

10. Epstein, B. and Lomnitz, C. (1966). A model for the occurrence of large earthquakes. Nature 211:954-956.

11. Fekadu Kebede and Kulhanek, O. (1994). Spatial and temporal variations of bvalues along the East African rift system and southem Red Sea. Phys. Earth Planetary Int. 83:249-264.

12. Gibson, I.L. (1967). A prelimenary account of the volcanic geology of Fentale, Shoa. Bull. Geophys. Obs. 10:59-67.

13. Gidey Woldegebriel, Aronson, J.L. and Walter, R.C. (1990). Geology, geochronology and rift basin development in the central sector of the Main Ethiopian Rift. Geol. Soc. Am. Bull. 102:439-455.

14. Gouin, P. (1971). Surface Cracks and subsidence in Mojjo. Report TR-011 to Ministry of the Interior, Ethiopia, 5 pp.

15. Gouin, P. (1979). The earthquake history of Ethiopia and the Horn of Africa. IDRC publication, Ottawa, Canada, p 258.

16. Gouin, P. and Mohr, P.A. (1967). Recent Effects possibly due to tensional separation in the Ethiopian Rift System. Bull. Geophys. Obs. 10:69-78.

17. Laike M. Asfaw (1982). Development of earthquake induced fissures. Nature 286:551-553.

18. Laike M. Asfaw (1998). Environmental hazard from fissures in the Main Ethiopian Rift. J. Afr. Earth. Sci. 27(3/4):481-490.

19. Laike M. Asfaw (1986). Catalogue of Ethiopian Earthquakes, earthquake parameters, strain release and seismic risk. In: Proc. SAREC-ESTC, pp. 252-279, (Gizachew Woldeyes, ed.) Addis Abeba, Ethiopia. 
20. Laike M. Asfaw, Bilham, R., Jackson, M. and Mohr, P. (1992). Recent inactivity in African rift. Nature 357:447.

21. Lloyds, E.F. (1977). Geology of the Main Ethiopian Rift. Report, Ethiopian Geological Survey, Addis Abeba, Ethiopia, 73 pp.

22. Mohr, P.A. (1967). Major volcano-tectonic lineament in the Ethiopian rift system. Nature 213:664-665.

23. Mohr, P., Girnius, A. and Rolff, J. (1978). Present day strain rate at the northern end of the Ethiopian Rift Valley. Tectonophysics 44:141-160.

24. Mohr, P. (1981). Geodetic measurement of recent crustal movement in the Central Ethiopian Rift Vally. SINET: Ethiop. J. Sci. 4(2):73-82.

25. Molnar, P., Fitch, T.J. and Laike M. Asfaw (1970). A micro earthquake survey in the Ethiopian rift. Earthquake Notes 41:37-44.

26. Morton, W.H., Rex, D.C., Mitchell, J.g. and Mohr, P. (1979). Riftward younging of volcanic units in the Addis Abeba region, Ethiopian Rift Valley. Nature 280:284-288.

27. Searle, R.C. and Gouin, P. (1972). A gravity survey of the central part of the Ethiopian Rift Valley. Tectonophysics 15:41-52.

28. Shudofsky, G.N. (1985). Source mechanisms and focal depths of East African Earthquakes, using Raleigh-wave inversion and body-wave modelling. Geophy. J.R. Astr. Soc. 83:563-614.

29. Williams, M. (1981). Recent Tectonically Induced Gully Erosion at K'one, Metehara-Wolenchiti area: Ethiopian Rift. Geophys. Obs. Report, p. 15. 